\title{
Lymphatic Medicine: Paradoxically and Unnecessarily Ignored
}

\author{
Stanley G. Rockson, MD
}

$\mathbf{L}^{\prime}$ AST MONTH, A CONSULTATION with a new patient engraved itself within my memory. The clinical presentation of his medical problem was not particularly unusual within the scope of my practice, but the circumstances surrounding his visit were striking. This retired gentleman had flown thousands of miles because, as he said, "You are my last hope." The patient recounted a nearly lifelong history of hereditary lymphedema, in itself not a rare disorder. In recent years, his medical problem had intensified with the advent of persistent chylous ascites that necessitated multiple therapeutic paracenteses each month. He traveled to Stanford with his wife, exhausted and desperate.

Why was this patient so memorable? It was the paradox surrounding his need for consultation with me. He did not have a rare or undiagnosed condition, and he did not come to me from some isolated medical backwater; rather, he had been receiving his medical care within a highly regarded, tertiary care multispecialty clinic. Nevertheless, he had been subjected to surgeries where conservative options had not been explored. When diagnostic imaging became indicated, his physicians opted for the highly invasive approach of lymphangiography when the gold standard, radionuclide lymphoscintigraphy, might certainly have sufficed. Ultimately, his doctors said, quite frankly, "We are failing you. You have to find another answer." They left it to the patient to find his own solution. Not only were they unable to provide the relatively simple, nonprocedural therapies indicated here, they were not even able to guide the patient to an appropriate resource for further evaluation and treatment. Sadly, this patient is not alone in feeling abandoned by the medical community.

How has this deplorable lymphatic ignorance arisen? It strikes me that the current level of lymphatic ignorance would not be predictable from the known course of medical history. Indeed, Aselli recognized the existence of the visceral lymphatic circulation a scant fifty years after William Harvey described the blood vasculature. ${ }^{1}$ In fact, if we search even farther back in medical history, we learn that the Father of Medicine, Hippocrates, not only recognized the lymphatic vessels as "white blood,"2 he even created the name chyle. Ironically, Hippocrates seems to have had fundamental insights that seem to be absent in the prior medical care delivered to my patient for his recurrent chylous ascites.

In stark contrast to these auspicious historical beginnings, the evolution of modern medical practice has not been kind to the lymphatic patient. Despite the heavy emphasis placed upon the functional importance of the lymphatics in Guyton's Textbook of Medical Physiology, ${ }^{3}$ studied by generations of medical students, the translation of this preclinical curriculum into the practice of medicine is quite faulty. It is disheartening to learn that the average American medical school graduate receives an exposure to the lymphatic curriculum for less than 30 minutes within a four-year medical education. ${ }^{4}$ Small wonder that so many lymphatic patients discover that their health care providers are ill-equipped to provide the care and solace that they seek. These inequities are especially tragic when the patient is a child whose diagnosis and indicated treatment is not available during critical formative years.

Unfortunately, the problems extend far beyond health care practitioners. While it has been incontrovertibly established that the progression of lymphedema and other lymphatic diseases can be halted or significantly slowed through treatment, our health care system denies access to these beneficial modalities to large numbers of affected Americans. The proper management of lymphedema, for example, is dependent primarily upon the lifelong utilization of compression garments and supplies. These durable medical goods must be replaced at least semi-annually, but they are routinely not reimbursed by third party payers, most notably Medicare. Similar barriers exist for access to highly efficacious modes of self-management, such as advanced intermittent pneumatic compression devices, despite the fact that these have been shown to both improve patient well-being and reduce utilization of medical resources and cost of care. ${ }^{5 ., 6}$ Thus, not only do lymphatic patients struggle with their poor access to knowledgeable providers, they are often unable to utilize the resources that exist to reduce symptoms, reduce progression, and prevent unnecessary complications.

This degree of medical neglect and ignorance should be unacceptable to all of us. We must acknowledge our duty to provide treatment and hope for the millions of Americans, and hundreds of millions globally, who seek answers as they attempt to cope with the stigmata of lymphatic disease.

Many of these inequities are paradoxical and can certainly be rectified. Insights into lymphatic biology and pathology are growing exponentially, as witnessed by the more than 5,000 manuscripts indexed in the National Library of Medicine in 2016. This deluge of new information brings the

Stanford University School of Medicine, Stanford, California. 
promise of newer, more precise diagnostic procedures and more efficacious medical and surgical therapies.

Existing treatment modalities can be more effectively and widely distributed. The failure of Medicare to reimburse the cost of durable medical supplies arises from the inability to classify them under any existing benefit category in the Medicare statute. This inequity is only rectifiable through federal legislation. The Lymphedema Treatment Act (LTA) is an active bill in the current, 115th Congress (HR 930 and S 497). The LTA, when enacted, will improve coverage for the treatment of lymphedema from any cause by amending the Medicare statute to create coverage for compression supplies; while the bill relates specifically to a change in Medicare law, it would set a precedent for Medicaid and private insurers to follow. As medical practitioners we must lend our enthusiastic support to this legislative process on behalf of our numerous, underserved lymphatic patients.

Finally, and most importantly, we must close the information gap so that our patients have access to knowledgeable and supportive physicians. Clearly, this will require curricular reform, which can be a slow process. While we await this much-needed development, we must avail ourselves of the existing resources. Fortunately, there is a wealth of didactic information available both in print and in media format. As one example, the Lymphatic Research and Education Network (LE\&RN) has sponsored a longstanding virtual lecture series in freely accessible, videotaped online format. ${ }^{7}$ Herein is contained a wealth of clinical information that can, in many ways, take the place of the material that is omitted from the current, formal training process for clinical specialists.
Creating a better world for lymphatic patients is not an idle dream. The tools already exist. In a future world of ideal medical practice, clinicians will receive the same exposure to the lymphatic system that they currently receive for cardiac, renal, endocrine, and other bodily functions. If not today, then tomorrow, we must be able to ensure that my lymphatic patient, and others like him, will receive the required high level medical care without the need for a 3,000 mile journey.

\section{References}

1. Aselli G. De Lactibus Sive Lacteis Venis. Milan: JB Bidellius; 1627.

2. Choi I, Lee S, Hong YK. The new era of the lymphatic system: No longer secondary to the blood vascular system. Cold Spring Harb Perspect Med 2012;2:a006445.

3. Hall JE. Textbook of Medical Physiology. 13th Edition ed. Philadelphia: Saunders; 2015.

4. Rockson SG, Granger DN, Skeff KM, Chaite W. Lymphatic biology and disease: Is it being taught? Who is listening? Lymphat Res Biol 2004;2:86-95.

5. Brayton KM, Hirsch AT, PJ OB, Cheville A, Karaca-Mandic P, Rockson SG. Lymphedema prevalence and treatment benefits in cancer: Impact of a therapeutic intervention on health outcomes and costs. PLoS One 2014;9:e114597.

6. Karaca-Mandic P, Hirsch AT, Rockson SG, Ridner SH. the cutaneous, net clinical, and health economic benefits of advanced pneumatic compression devices in patients with lymphedema. JAMA Dermatol 2015;151:1187-1193.

7. LE\&RN Symposium series. (Accessed August 27, 2017). 